\title{
ERRATUM
}

\section{Emerging Neurosurgery in Africa - WFNS Rabat Reference Center (WFNS-RTC) for Training African Neurosurgeons}

TO THE READERSHIP: Errors appeared in the book review by Lohkamp and Rutka (Lohkamp LN, Rutka JT. Emerging Neurosurgery in Africa - WFNS Rabat Reference Center (WFNS-RTC) for Training African Neurosurgeons. J Neurosurg. 2020;133[1]:257-258).

In the second paragraph, the number of inhabitants of the Democratic Republic of Congo is 60 million, not 6 million. The corrected sentence appears below.

Such was written about Dr. Didier Mudjir Balanda, the second neurosurgeon in a country of 60 million inhabitants, serving the Democratic Republic of Congo after having been trained at the WFNS-Rabat Reference Center for Training African Neurosurgeons.

In the third paragraph, the sentence about the neurosurgeons practicing in Africa was misleading. A more accurate statement appears below.

At the end of the last century (1998), there were only 79 neurosurgeons practicing within SubSaharan Africa with a population base of 615 million inhabitants.

James T. Rutka, MD, PhD

Published online September 4, 2020; DOI: 10.3171/2020.8.JNS208000a.

CAANS 2020, except where prohibited by US copyright law 